\title{
PATTERN OF MAJOR JOINTS DISLOCATIONS SEEN IN A TERTIARY HOSPITAL IN ENUGU, NIGERIA.
}

\author{
OKENWA WILFRED O. [greatson2002@yahoo.com]
}

\author{
EDEH ANTHONY J. [nkanuwest@ gmail.com] \\ Department Of Surgery \\ ESUT Teaching Hospital, \\ Park Lane Enugu, Nigeria. \\ Corresponding Author: Okenwa Wilfred O. \\ +2348038725190. greatson2002@yahoo.com \\ DOI: $10.31364 / S C I R J / v 7 . i 4.2019 . P 0419638$ \\ http://dx.doi.org/10.31364/SCIRJ/v7.i4.2019.P0419638
}

\begin{abstract}
Dislocation of a joint is the total disruption of that joint such that bones forming the joint are no longer in contact. The disruption is usually due to application of an unexpected or an unbalanced force to the joint. In America and Europe the shoulder joint is the most dislocated joint. Need to document pattern of major joint dislocations and their causes in our environment prompted this work. Data was collected using the medical records of the hospital via patients' folders, Ward admission registers and Theatre registers of patients admitted from January 2007 to December 2016. The inclusion criteria were all patients admitted into the hospital with closed dislocation due to trauma. Only dislocations involving major lower and upper limb joints were considered. Open dislocations were excluded. 124 patients with 126 dislocations involving 82 males and 42 females were found. The commoner forms of dislocations noted were hip dislocation 84 cases (66.7\%) and shoulder dislocation 20 cases (15.8\%). Dislocations were seen most in the third decade life.
\end{abstract}

One patient had hip and shoulder dislocation simultaneously and another had bilateral hip dislocations.

Key Words: Major joints, dislocations, road traffic accidents, Enugu Nigeria.

\section{INTRODUCTION}

Human joints are points in the body where two or more bones are connected to one another, usually for the purpose of movement of the body. It permits movement of the skeletal system as a whole. Moveable joints are lined by cartilage and held together by strong elastic tissues, capsules and ligaments. Disruption of major joints resulting in dislocation is regarded as an orthopaedic emergency and immediate diagnosis and necessary interventions make a lot of difference in the outcome of patient management $[1,2,3]$. All joints are prone to dislocations but some are more likely to dislocate than others in a given circumstance. Major joints of the lower and upper limbs are involved in everyday activity that they are virtually exposed to disruption in a variety of situations. Road traffic accidents, sporting injuries, domestic accidents, falls from height and other high energy activities are known to be among the causes of joint dislocations. These activities and events take place usually at the peak of youth and invariably affect their productivity, source of their livelihood and their daily economic survival. Therefore early restoration of joint function, following dislocation has beneficial effects on the survival of the person involved [4]. Several reviews assign the 
most commonly dislocated joint to the shoulder joint $[1,5,6]$. This is believed to be due to the anatomical peculiarities of the shoulder joint. In the shoulder joint, the articular surface of a relatively big head of humerus articulates with the relatively shallow glenoid cavity of the scapula. Though the shoulder joint is stabilised by the glenoid labrum, ligaments and muscles which connects the humerus to the scapula, it still has the widest range of movements of all the joints in the body. This increased range of movement perhaps predisposes it to more dislocations.

Clearly, each time a joint is dislocated, the ligaments and capsules keeping the joint in position gets stretched and loosened making it easier for the joint to be dislocated again. The joint becomes more unstable with subsequent dislocations.

The aim of this study is to document the pattern of major joints dislocation in Enugu, South East Nigeria and compare it to what is obtainable in other parts of the world. There is paucity of information on major joints dislocations in our environment so this work may serve as a source of records and may be useful in awareness creation.

\section{MATERIAL AND METHOD}

This is a retrospective study covering the period from January 2007 to December 2016. Data was collected using patient's records as seen in the folders, ward admission registers, theatre registers and accident and emergency unit records. Information obtained from the records included, the joints involved, causes of injury or trauma, age and sex of patients, treatments offered, associated injuries and complications. Major upper limb and lower limb joints were included. Dislocations involving the digits, and open dislocations involving the major limb joints were excluded.

\section{RESULT}

124 patients with 126 dislocations were found in the study. Two patients had multiple dislocations. One patient had bilateral hip dislocations, while the other had a hip dislocation and a shoulder dislocation. 82 cases (66.1\%) were males and 42 cases (33.9\%) were females.

The most commonly dislocated joint (Table 1) is that of the hip with 84 cases (66.7\%), followed by dislocation of the shoulder with 20 cases $(15.9 \%)$ and that of the elbow with 08 cases $(6.3 \%)$. In the hip dislocations, the most common type is posterior hip dislocation with 74 cases $(88.1 \%)$, then central hip dislocation with 8 cases $(9.5 \%)$, and anterior hip dislocation with 2 cases $(2.4 \%)$.

A variety of causes are known to account for these injuries. They include road traffic accidents, falls from heights, sports injuries, and Domestic violence as well as assaults (Table 2). Road Traffic accident is the commonest cause of dislocations and it was implicated in 88 cases $(71 \%)$ of these injuries. This was followed by falls from heights with 20 cases (16.1\%).

Occurrence of dislocations cut across all ages (figure 1). In this study, it is seen from the teenage years to the eighth decade of life. The age group most commonly affected is the $21-30 y e a r s$ group with 44 cases $(35.5 \%)$. This is followed by the $31-40$ years group with 32 cases $(25.8 \%)$ and the 41-50years group with 24 cases $(19.4 \%)$.

75(59.5\%) dislocations presented within 12 hours of injury, 27 cases (21.4\%) within 12-24 hours, 10 cases (8.0\%) within 24-4hrs, 09 cases $(7.1 \%)$ within 1 week and 5 cases $(4.0 \%) 4$ weeks after injury. $80 \%$ of those that presented after 24 hours of dislocation showed signs of osteoarthritis at one year follow up.

Majority of the dislocations $82(97.6 \%)$ of hip and $17(85.0 \%)$ of shoulder were treated by closed reduction. Only 3 cases (15\%) of shoulder dislocations and 2 cases $(2.4 \%)$ of hip dislocations were treated by open reduction after closed reduction was not successful. Reduced hips were put on skeletal traction for $6-8$ weeks and mobilised first on non-weight bearing crutches and full 
mobilisation after 12 weeks. Reduced shoulders were strapped with elastic bandage for about a week after which rehabilitation commenced with appropriate physiotherapy. Reduced knees and ankles were immobilised in plaster of Paris or fibre glass casts for variable lengths of time (4-6 weeks) and then mobilised on partial weight bearing. Majority of patients recovered full joint function.

Table 3 outlines the different forms of hip dislocation seen in this study, posterior hip dislocation accounting for the commonest.

Table 4 shows other injuries associated with the dislocations, lacerations/abrasions being the commonest.

After an average follow up period of 18months, post traumatic osteoarthritis was noted in 6 hips, 4 shoulders and 1 knee. Avascular necrosis was seen in 1 femoral head and foot drop likely due to sciatic nerve injury was seen in 2 patients. Recurrent dislocation was seen in 2 shoulders and 1 hip. Volkmann ischaemic contracture of the forearm was seen in a patient who presented 4 days after tight splinting of the arm by a native bone setter.

Figure 1. Age distribution of joint dislocation

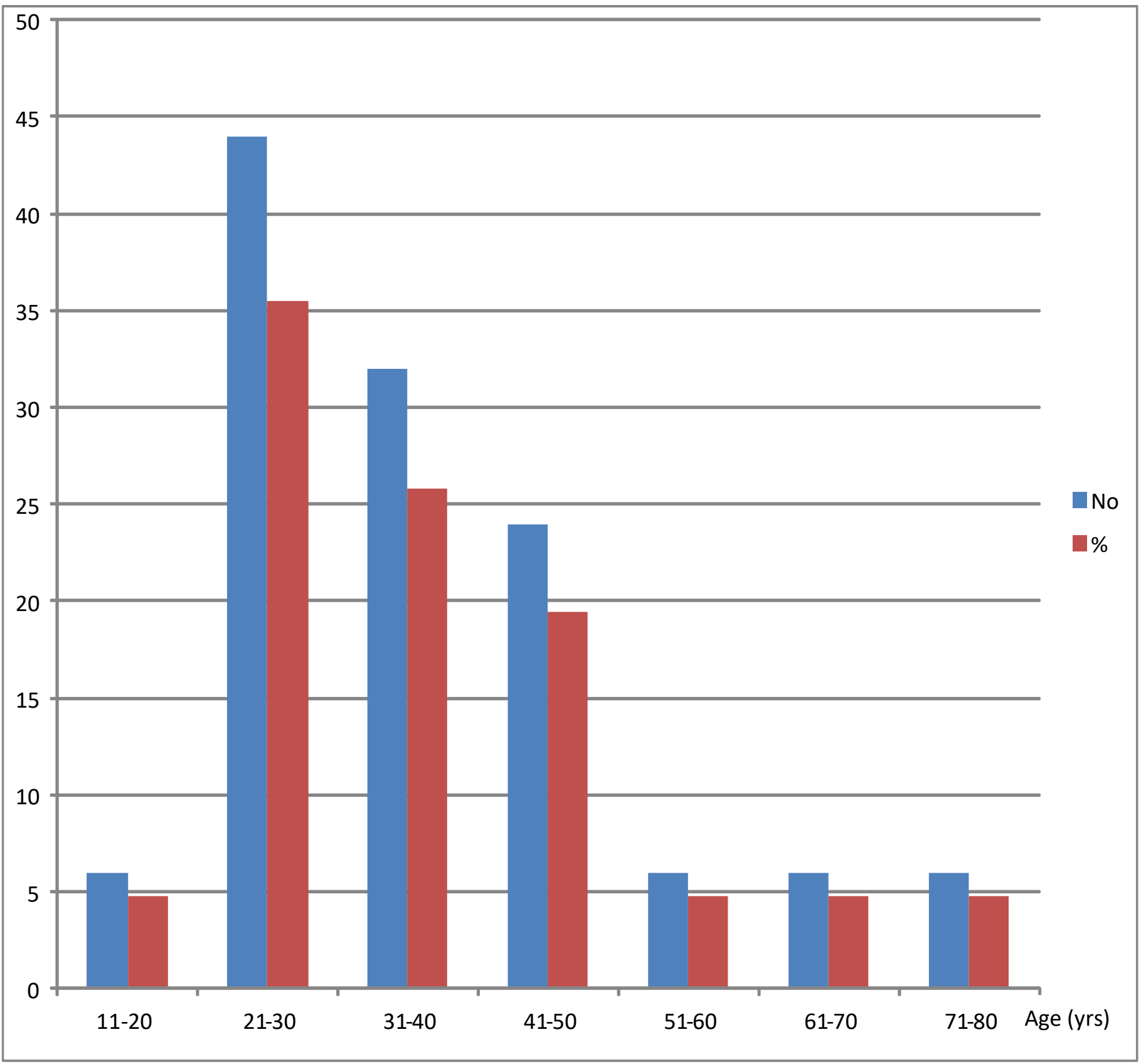


Table 1. Types of Dislocation

\begin{tabular}{|l|l|l|l|l|}
\hline Types of Dislocation & Sex & Female & Number & $\%$ \\
\hline Hip & 68 & 16 & 84 & 66.7 \\
\hline Shoulder & 4 & 16 & 20 & 15.9 \\
\hline Elbow & - & 8 & 8 & 6.3 \\
\hline Wrist & - & 4 & 4 & 3.2 \\
\hline Knee & 2 & - & 2 & 1.6 \\
\hline Ankle & 4 & 4 & 8 & 6.3 \\
\hline Total & 78 & 48 & 126 & $100 \%$ \\
& & & & \\
\hline
\end{tabular}

Table 2. Causes of Dislocation

\begin{tabular}{|l|l|l|}
\hline Cause of Trauma & Number & $\%$ \\
\hline Road Traffic Accident & 88 & 71 \\
\hline Fall From Height & 20 & 16.1 \\
\hline Routine Movement & 4 & 3.2 \\
\hline Sports & 6 & 4.8 \\
\hline Domestic Violence & 4 & 3.2 \\
\hline Assault & 2 & 1.6 \\
\hline Total & 2 & 100 \\
\hline
\end{tabular}


Table 3. Types of hip Dislocation

\begin{tabular}{|l|l|l|l|}
\hline Hip Dislocation & Right & Left & $\%$ \\
\hline Posterior & 28 & 46 & 88.1 \\
\hline Anterior & 2 & 0 & 2.4 \\
\hline Central & 4 & 4 & 9.5 \\
\hline Total & 34 & 50 & 100 \\
\hline
\end{tabular}

Table 4. Associated Injuries

\begin{tabular}{|l|c|}
\hline Type of Injury & No \\
\hline Faceration/Abrasions & 8 \\
Chest/Abdomen & 5 \\
Extremities & 15 \\
\hline Head Injury & 3 \\
\hline Fractures & 1 \\
Humerus & 3 \\
Radius/Ulna & 2 \\
Femur & 2 \\
Tibia/ Fibula & 3 \\
Ribs & 11 \\
Pelvic & \\
\hline Nerve & \\
\hline Total & \\
\hline
\end{tabular}




\section{DISCUSSION}

Most joints in the human body are prone to dislocation, however, some are more likely to dislocate than others. The movement of bones against each other at the joints make it possible for humans to achieve locomotion. Some joints like the shoulder have wide range of movement and are particularly quite mobile. Other joints like carpal joints have small range of movement and usually in one direction. Clearly, there seem to be a correlation between mobility and stability in joint dislocation as joints that are very mobile tend to dislocate more often than those that are relatively rigid.

In this review, we noted 126 dislocations involving major joints of the upper and lower limbs over a ten year period. Our review to the best of our knowledge is the only review of dislocations involving major joints in our immediate environment. We noted, that the commonest joint dislocated in our series is the hip joint 84 cases $(66.6 \%)$ while the shoulder joint accounted for 20 cases (15.9\%) of the series. This differs sharply with some other studies that put the shoulder joint ahead as the most commonly dislocated joint in the body [1, 5, 6]. However, Sadat Ali et al [9] in their work noted a result similar to ours where hip dislocation was commoner than shoulder dislocation. This difference may be due to poor development of sporting activities involving the use of the upper limb more than the lower limb in our environment. Also because it is relatively easier to reduce a dislocated shoulder outside the hospital, shoulder dislocation patients may not ultimately present in the hospital. This reluctance to present in hospital is in line with locally held belief that orthodox medicine has poorer knowledge of bone related pathologies when compared with traditional bone setters.

Dislocation of the joint is commonly caused by road traffic accidents, in our study. This differs significantly from studies in Europe and America [7] where sports injury is the commonest cause of dislocations ranking, road traffic accidents and falls from heights second and third respectively. A poorly developed road infrastructure, poorly maintained vehicles, poor driving culture and habit in our environment may be blamed. Vehicles in our environment are commonly overloaded, speed limits are not obeyed, alcohol and drug abuse are common among drivers making driving a huge task and accidents common. Some pedestrians are equally not mindful of dangers associated with improper road behaviour as many ignore the use of pedestrian overhead bridges provided for safe crossing of busy roads. Some pedestrians also completely ignore road signs assuming, that it is the responsibility of the vehicle driver to avoid them.

Yang et al [8] working in Taiwan noted that 42.1/100,00 population of all joint dislocations were as a result of road traffic accidents, making road traffic accidents the commonest cause of dislocations in Taiwan. Sadat -Ali [9] working in Saudi Arabia and Okaro [10] working in Owerri Nigeria also recorded road traffic accident as the commonest cause of joint dislocations in a study in Saudi Arabia. The commonest cause of dislocation and the joint that dislocate most commonly differ from place to place and tend to reflect the socio economic circumstance of the area.

Further analysis of hip dislocation in our study shows that posterior dislocation is the commonest type of hip dislocation $88.1 \%$. This is very similar to another study by Onyemaechi et al [11], in a regional Trauma Centre in Nigeria.

Many authors believe that immediate diagnosis and reduction of dislocated joints can result in improved patients' outcome [2, 4]. Several researchers believe that the critical time between the trauma /injury and reduction of the dislocation should be within 12hours [14, 15]. However Yang et al [16] could not find any obvious statistical difference between treatment outcomes of patients' treated within 12 hours and those treated within 24hours, for hip dislocation. In our study, 68 cases (80.9\%) of hip dislocations presented and were promptly managed within 24 hours of the injury. This gave them a very good opportunity to have good recovery. There was no clear cut difference in outcome between dislocations reduced within 12 hours and the ones reduced within 24 hours after one year of follow up. Those that were reduced after 24 hours had started showing signs of osteoarthritis one year post injury. It will be safe to say that 'the sun should not rise and set over a dislocated hip' in other to reduce the likelihood 
of post traumatic osteoarthritis. We can safely advice, that every dislocated major joint should be reduced as soon as possible preferably within 12 hours of the dislocation.

Based on the result of this study which showed that road traffic accident is the commonest cause of injury, there is need to put in place measures that will prevent or reduce the rate of RTA. The measures should be strictly enforced and defaulters appropriately sanctioned. We advocate proper training of drivers, enforcement of drivers licensing programme and overall enlightenment of road users on road safety practices. Provision of appropriate road infrastructure should be given attention. In addition to the measures above, we also advice the followings; installing speed limiting devices in all vehicles, use of seat belts, ban of sale of alcohol and hard drugs in our garages and testing suspected drunk drivers on our highways. The need for all road users to be more careful while on the road cannot be over emphasised as human error has been implicated in $80 \%$ of road crashes [12].

Studies on joint dislocation should be encouraged as that seem to be the least studied topic in orthopaedic surgery [9], despite the importance joints in human anatomy.

Our study has this limitation that it is one centre based however it is hoped that it can stimulate insight into the problems of joint dislocation in our environment as in other developing countries.

\section{CONCLUSION}

The commonest type of joint dislocations managed in our centre is hip dislocation and dislocations generally are more likely to occur as a result of road traffic accidents. It is therefore necessary that all road users should be more careful when they are on the road by ensuring road safety consciousness.

The dislocations tend to occur in the more economically active age group and this could impact negatively on the lives of the people.

However, when major limb dislocation occur, it will be ideal to reduce them within 12 hours.

\section{REFERENCES}

1. Khiami F, Gerometta A, Loriaut P. Management of recent first time anterior shoulder dislocation. Orthopaedics and Traumatology; Surgery and Research.101 (1):S51-S57.doi:10.1016/j.otsv.2014.06.027.

2. Hodge DK, Sarfan MR. Side-line management of common dislocations. Curr Sports Rep. 2002; 1:149-155 (Pub Med)

3. Itoi E, Hatakeyama Y, Sao T, et al. Immobilisation in external rotation after shoulder dislocation reduces risk of recurrence. A randomised controlled trial. J Bone Joint Surg Am.2007; 89: 2131. (Pub Med).

4. Luke A, Micheli L. Sports Injuries: emergency assessment and field -side care. Pediatr Rev.1999; 20:291-300 (Pub Med)

5. Benjamin HJ, Hang BT. Common acute upper extremity injuries in Sports. Clin Paediatric Emerg Med. 2007; 8 (1):15-30

6. Nathan W. Skelley, Jeremy J. McCormick, Mathew V.SMITH. In-game management of common joint dislocations. Sport Health. 2014; 6(3): 246-255.

7. Kerr ZY, Collins CL, Comstock D. Epidemiology of Dislocations/Separation among US high School athletes. Injury Prev. 2011; 16(Suppl 1): A255-A256. 
8. Yang NP, Chen HC, Phan DV, Yu IL, Chan CL, et al. Epidemiology survey of Orthopedic joint dislocations based on nationwide insurance data in Taiwan, 200-2005.BMC Musculoskelet Disord 2011;12:253.

9. Sadat-Ali M, Alomran AS, Azarn Q, All SayedHn, Ai Dhafer BA, Kubbara AF, AI Shanikh SH. Epidemiology of fractures and dislocations among Urban Communities of Eastern Saudi Arabia. Saudi J Med Sci 2015;3:547.http:/www.sjimms.net/test.asp.2015/3/1/54/149682.

10. Okaro I0, Ohadugha C.O. The anatomic pattern of fractures and dislocation among accident victims in Owerri. Nig J. Sug Res. 2006; 54-56.

11. Onyemaechi NOC, Eyichukwu GO. Traumatic hip dislocations a Regional Trauma Centre in Nigeria. Nig J Med; 2011; 20:124-30.

12. Ansari S, Akhdar F, Mandoorah M, Moutaery K. Cause and effect of road traffic accidents in Saudi Arabia. Public Health 2000; 114:37-9.

13. Zacchilli MA, Owens BD. Epidemiology of shoulder dislocations presenting in emergency departments in the United States. J Bone Joint Surg Am 2010;92:542

9

14. Brav EA. Traumatic Dislocation of the hip. Army experience and result over a 12months period. J Bone Joint Surg Am.1962; 44 1115-8.

15. Epstein HC. Posterior fracture dislocation of the hip: Long term follow-up. J Bone Joint Surg .Am 1974; 56:

16. Yang RS. Tsuang YH, Hang YS, et al. Traumatic dislocation of hip. Clin Orthop.1991; 265:218-27 